\title{
Intraoperative blood transfusion on long-term outcomes of liver transplantation for hepatocellular carcinoma
}

Wing Chiu Dai (MBBS) ${ }^{1}$

Kenneth SH Chok (MBBS, MS) ${ }^{1}$

Sui Ling Sin (MBChB) ${ }^{1}$

Albert CY Chan (MBBS) ${ }^{1}$

Tan To Cheung (MBBS, MS) ${ }^{1}$

Tiffany CL Wong (MBChB) ${ }^{1}$

See Ching Chan (MBBS, MS, PhD, MD) ${ }^{1}$

Chung Mau Lo (MBBS, MS) ${ }^{1}$

${ }^{1}$ Department of Surgery, The University of Hong Kong, Hong Kong, China

Running title: Impact of transfusion on long-term outcomes of transplant for HCC

Keywords: liver transplantation; hepatocellular carcinoma; outcomes; blood transfusion; survival

Grants and other financial support: This study received no grant or financial support.

This paper was presented at the $2^{\text {nd }}$ International Congress of Living Donor Liver Transplantation Study Group in Seoul, Korea, 7-8 November 2015.

Corresponding author: Dr. Kenneth Siu Ho Chok (Address: 102 Pok Fu Lam Road, Hong Kong, China. Telephone: 22553025; Facsimile: 28165284; Email: kennethchok@gmail.com) 


\section{ABSTRACT}

Objective: To investigate the impact of intraoperative blood transfusion on the long-term outcomes of liver transplantation for hepatocellular carcinoma.

Method: Adult patients who had non-salvage liver transplantation at our center between January 2005 and December 2012 for hepatocellular carcinomas that were within the UCSF criteria and could not be resected or ablated were divided into groups with and without intraoperative blood transfusion. Comparisons were made between groups.

Results: Ninety-nine patients were included in the study. Sixty-two (62.6\%) patients received intraoperative blood transfusion. Patients without transfusion were younger (54 vs. 56 years; $\mathrm{p}=0.04$ ) and had a lower Model for End-stage Liver Disease score (11 vs. 14; $\mathrm{p}<0.001$ ). More of them had stage- 1 tumors (64.9\% vs. 37.1\%; $\mathrm{p}=0.007)$ and fewer of them had postoperative complications of grade IIIA or above in the Clavien-Dino classification (21.6\% vs. 48.4\%; $\mathrm{p}=0.008)$. The groups were comparable in hospital mortality ( $3.2 \%$ vs. $2.7 \% ; \mathrm{p}=1.00)$, 5-year overall survival (90.8\% vs. 89.2\%; p=0.611), and 5-year disease-free survival (90.5\% vs. 89.2\%; $\mathrm{p}=0.835$ ). On multivariate analysis, postoperative complications of grade IIIA or above were associated with worse survival (hazard ratio 7.108; 95\% confidence interval 1.455-34.712; $\mathrm{p}=0.015)$.

Conclusion: Intraoperative blood transfusion was shown to have no significant impact on the long-term outcomes of liver transplantation for hepatocellular carcinoma, whereas postoperative complications of grade IIIA or above were associated with worse recipient survival. 


\section{Introduction}

It has been reported that blood loss and blood transfusion during hepatectomy for hepatocellular carcinoma (HCC) promote disease recurrence and worsen postoperative overall and disease-free survival [1-11]. Harmful effects of perioperative blood transfusions on recurrence of other malignancies have also been reported [12-25]. It is speculated that perioperative blood transfusions cause immunomodulation reactions and thus have a deleterious effect on the recurrence of malignancies and the survival of patients.

The proportion of patients who undergo liver transplantation for HCC is increasing and HCC comprises one third of the indications for liver transplantations in Asia [26]. Liver transplantation remains a surgical procedure associated with major bleeding despite recently improved understanding and management of coagulation defects [27, 28]. The association between blood transfusion and recurrence-free survival after transplantation for HCC remains controversial.

This retrospective study was conducted to investigate the relation between perioperative blood transfusion and overall and disease-free survival after liver transplantation for HCC.

\section{Patients and Methods}

Our objective was to investigate intraoperative blood transfusion requirement as a risk factor for overall survival after liver transplantation, and to identify independent risk factors associated with overall survival using logistic regression.

Included in the study were adult patients who had non-salvage liver transplantation at the Department of Surgery, The University of Hong Kong, for HCCs that were within the UCSF (University of California, San Francisco) criteria and could not be resected or ablated. The study period was from January 2005 to December 2012.

The strategies adopted for selection of patients with known HCC for transplantation have been described elsewhere [29, 30]. In brief, tumor evaluation was done with computed 
tomography of the abdomen and thorax, in addition to radionuclide bone scan at initial diagnosis. In recent years dual-tracer [11C-acetate and 18F-fluorodeoxyglucose (FDG)] positron emission tomography were performed to exclude extrahepatic metastasis. There was no mandatory waiting period prior to liver transplantation and bridging therapy with transarterial chemoembolization was offered to those listed for liver transplantation with reasonable liver function.

Trigger for the administration of packed red blood cells was not standardized and relied entirely on the assessment of the overall clinical situation by the individual highly experienced surgeons in charge. We used only allogenic blood for transfusion and cell-saved blood was not used for patients with known hepatocellulcar carcinoma.

\section{Definitions}

Blood transfusion: Only transfusion of red cell concentrate was regarded as blood transfusion. Transfusion of other blood products (fresh-frozen plasma, platelets, or albumin) was not considered blood transfusion.

Operative mortality: Death occurring within 30 days of transplantation.

Complication: Postoperative complications were defined and classified according to the modified Clavien-Dindo classification [31]. Briefly, grade I is any deviation from the normal postoperative course not requiring any special treatment. Grade II complications are those requiring pharmacological treatment. Grade III complications are complications that require surgical or radiological intervention with (IIIB) or without (IIIA) general anesthesia. Grade IV refers to life-threatening complications involving single (IVA) or multiple (IVB) organ dysfunction. Grade V is death of the patient.

As postoperative complication was concerned, the patients were divided into two groups: those with no complications or only grade-I or grade-II complications, and those with complications of grade III or above. In the case of multiple complications in a patient, the 
complication grade was based on the most serious complication.

\section{Statistical analysis}

Continuous variables were expressed as medians and ranges and compared by the Mann-Whitney U test. Pearson’s chi-squared test was used to compare categorical variables. Survival analysis was performed using the Kaplan-Meier method and compared between groups by the log-rank test. A multivariable analysis by Cox regression (step-wise forward model) was performed for variables reaching significance on univariate analysis that impacted upon overall survival. All analyses were performed by PASW Statistics for Windows, version 18.0 (SPSS, Chicago, IL, USA). Statistical significance was indicated by p values $<0.05$.

\section{Results}

A total of 99 patients underwent liver transplantation for HCC. The median follow-up period was 42.9 (0.9-108.1) months. Amongst them, 61 underwent living donor liver transplantation (LDLT) and 38 underwent deceased donor liver transplantation (DDLT). The median waiting time to transplantation was $0.89(0.03-56)$ months for our LDLT patients and $7.98(0.03-90)$ months for the DDLT patients. 9 (14.8\%) and 18 (47.4\%) underwent bridging therapy prior to the LDLT and DDLT respectively.

Intraoperative blood transfusion was given to 62 (62.6\%) patients. A comparison of demographic and perioperative clinical data between patients with and without intraoperative blood transfusion is shown in Table 1.

Figure 1 and Figure 2 are Kaplan-Meier plots of the overall survival and disease-free survival of the patients respectively. Compared with their counterparts, patients who received intraoperative blood transfusion showed no differences in terms of hospital mortality (3.2\% vs. 2.7\%; $p=1.00$ ), 5-year overall survival (90.8\% vs. 89.2\%; $p=0.611)$, and 5-year disease-free 
survival (90.5\% vs. 89.2\%; $\mathrm{p}=0.835)$. The 1-year, 3-year and 5-year graft survival was $95.2 \%$, 95.2\% and 90.8\% for the patients who received intraoperative blood transfusion and 94.6\%, 89.2\% and 89.2\% for those without intraoperative blood transfusion $(\mathrm{p}=0.611)$.

Table 2 shows the results of univariate and multivariate analyses of risk factors associated with overall survival. On multivariate analysis, the presence of a postoperative complication of grade IIIA or above was the only factor associated with worse survival (hazard ratio 7.108; 95\% confidence interval 1.455-34.712; $\mathrm{p}=0.015)$.

\section{Discussion}

It has been reported that blood loss and blood transfusion during hepatectomy for HCC promote disease recurrence and worsen postoperative overall and disease-free survival [1-11]. Similar findings have also been made with malignancies of the breast, the stomach, and the colon and rectum [12-25]. It is speculated that perioperative blood transfusions cause immunomodulation reactions and thus have a deleterious effect on the recurrence of malignancies and the survival of patients, which was demonstrated in recent studies [30-34].

Experimental animal models have suggested that immunomodulation associated with allogeneic blood transfusion is primarily related to the infusion of allogeneic leukocytes [35]. It may be mediated by allogeneic mononuclear cells, soluble mediators derived from white blood cells, and soluble HLA peptides circulating in allogeneic plasma [36]. Transfusion of allogeneic whole blood products has been shown to induce variations in certain immune functions [37, 38], such as reduced NK cell activity, T lymphocyte blastogenesis, and increased suppressor T lymphocyte activity, which may impair host resistance to infection and the spread of neoplastic cells.

Blood loss during liver transplantation is usually high due to portal hypertension and intra-abdominal varices as a consequence of end-stage liver failure, in addition to clotting 
disorders related to liver failure. Even though emphasis has been placed on reducing blood loss during the procedure, it still carries a risk of excessive blood loss, which is associated with higher risks of mortality, infectious complications, postoperative multi-organ dysfunction, early surgical re-intervention, and reduced graft survival [32-41]. Rana et al. [42] recently reported that intraoperative blood loss was an important risk factor for mortality after liver transplantation. However, studies on the influence of intraoperative allogeneic blood transfusion on cancer recurrence and patient survival after transplantation for HCC are scarce, and the topic remains controversial [43].

In our current study, the long-term (5-year) overall survival and disease-free survival were similar between patients with and without intraoperative blood transfusion, which is different from results reported by studies on hepatectomy. There may be various reasons. Firstly, although all the patients had HCC, those who received hepatectomy and those who received transplantation were two distinct groups of patients. In HCC patients undergoing hepatectomy, those who need transfusion generally have larger lesions that either are close to the vena cava or require major resection, while those who do not need blood transfusion usually have smaller, more peripheral lesions that can be resected under close hemostatic control. Various factors (e.g. preoperative level of serum alpha-fetoprotein, tumor size, tumor number, tumor cell differentiation, and the incidence of vascular invasion or liver cirrhosis) could have biased the results of those studies. When clinicopathological biases were adjusted, the overall survival rates of transfused patients were not significantly lower than those of non-transfused patients [44, 45]. In our study, all the patients were within the UCSF criteria. Although the non-transfused group had significantly more stage-I tumors compared with the transfused group, preoperative level of serum alpha-fetoprotein, tumor size, tumor differentiation, and the incidence of vascular permeation were comparable between the two groups. The major determinant for blood transfusion might be more related to the Model for End-stage Liver Disease scores of the patients (a median of 14 in the transfused group 
vs. 11 in the non-transfused group; $\mathrm{p}<0.001$ ) rather than the tumors.

Secondly, since all the transplant recipients were put on immunosuppressants in the postoperative period, the immunomodulatory effect of allogeneic blood transfusion might not be as significant as that in patients who received hepatectomy. However, despite the blood transfusions and the immunosuppressants, we were able to achieve a 5-year disease-free survival rate of $90.5 \%$ in the transfusion group and $89.2 \%$ in the non-transfused group $(\mathrm{p}=0.835)$.

Thirdly, in spite of the improvement in transplant techniques, blood loss during liver transplantation remains an issue. On the contrary, the problem of blood loss during hepatectomy has improved greatly. At our center, the overall transfusion rate for hepatectomy was $55.4 \%$ before 1999 but has reduced to $13.6 \%$ after 1999 [46]. A high-volume center in Japan also made a similar finding [47]. However, $63 \%$ of the transplant recipients in our current study required blood transfusion. The relatively small number of non-transfused patients has limited the power of the study.

There is another important finding in this study. The presence of a postoperative complication of grade IIIA or above was the only clinicopathological factor with an independent influence on overall survival. Postoperative complications may have adverse effects on the long-term outcomes of various kinds of surgery, including that for HCC and colorectal cancer [48]. In another study, specifically postoperative sepsis was shown to be an independent predictor of disease-free and overall survival after hepatic resection for colorectal liver metastasis [49]. The mechanism underlying the effects of postoperative complications on overall survival remains to be elucidated. It has been postulated that blood transfusion and septic complications might lead to a period of immunosuppression, which might in turn lead to disease recurrence and patient death [50]. In fact, previous studies have shown a correlation between blood transfusion and complication development [51-54]. Further clinicoimmunological studies would be helpful in elucidating exactly how postoperative complications increase the risk of poor long-term survival. 
This study has a number of drawbacks. It has a retrospective nature, a small sample size, and a heterogeneous patient population. In addition, it is a single-center study with inevitable selection bias. Nonetheless, it has shed some light on the survival outcome of HCC patients with and without blood transfusion during liver transplantation.

\section{Conclusion}

Transfusion of allogeneic blood has been reported to be associated with potentially devastating complications such as infections, transfusion reactions, and pulmonary edema. However, this study has shown that perioperative blood transfusion may not be a poor prognostic factor for tumor recurrence and overall survival for recipients of liver transplantation for HCC. However, the adverse effect of serious postoperative complications on long-term survival outcome has highlighted the importance of good perioperative care and meticulous surgical techniques in the avoidance of morbidity. 
Table 1. Comparison of demographic and perioperative clinical data of the two groups of patients

\begin{tabular}{|c|c|c|c|}
\hline & $\begin{array}{l}\text { With transfusion } \\
\qquad(n=62)\end{array}$ & $\begin{array}{l}\text { No transfusion } \\
\quad(n=37)\end{array}$ & $\mathbf{P}$ \\
\hline Age (years) & $56(30-65)$ & $54(40-67)$ & 0.040 \\
\hline Male : Female & $48: 14$ & $34: 3$ & 0.065 \\
\hline \multicolumn{4}{|l|}{ Etiology } \\
\hline Hepatitis B virus & 45 (72.6\%) & 32 (86.5\%) & \multirow{7}{*}{0.055} \\
\hline Hepatitis C virus & $10(16.1 \%)$ & $3(8.1 \%)$ & \\
\hline Hepatitis B and C viruses & $1(1.6 \%)$ & $1(2.7 \%)$ & \\
\hline Cryptogenic & $2(3.2 \%)$ & 0 & \\
\hline Alcoholic & $2(3.2 \%)$ & $1(2.7 \%)$ & \\
\hline Autoimmune hepatitis & $1(1.6 \%)$ & 0 & \\
\hline Primary biliary cirrhosis & $1(1.6 \%)$ & 0 & \\
\hline Model for End-stage Liver Disease score & $14(6-37)$ & $11(6-17)$ & $<0.001$ \\
\hline Alpha-fetoprotein (ng/ml) & $15(1-11210)$ & $25(2-3114)$ & 0.483 \\
\hline Number of tumor & $1(1-3)$ & $1(1-3)$ & 0.034 \\
\hline Largest size of tumors (cm) & $2.5(0.9-5.5)$ & $2.3(1-6.5)$ & 0.772 \\
\hline Vascular permeation & $16(25.8 \%)$ & $9(24.3 \%)$ & 0.870 \\
\hline Differentiation & & & 0.347 \\
\hline Well differentiated & $19(30.6 \%)$ & $16(43.2 \%)$ & \\
\hline Moderately differentiated & $34(54.8 \%)$ & $16(43.2 \%)$ & \\
\hline Poorly differentiated & $5(8.1 \%)$ & $1(2.7 \%)$ & \\
\hline No data & $4(6.5 \%)$ & $4(10.8 \%)$ & \\
\hline Tumor-node-metastasis staging & & & 0.007 \\
\hline Stage I & $23(37.1 \%)$ & 24 (64.9\%) & \\
\hline Stage II & $39(62.9 \%)$ & $13(35.1 \%)$ & \\
\hline Live donor graft : Deceased donor graft & $34: 28$ & $27: 10$ & 0.073 \\
\hline Graft weight (g) & $727.5(395-1800)$ & $650(350-1975)$ & 0.316 \\
\hline Cold ischemic time (min) & $144(71-633)$ & $120.5(82-447)$ & 0.114 \\
\hline Warm ischemic time (min) & $50.5(26-108)$ & $53(35-70)$ & 0.356 \\
\hline Operation duration (min) & $663(300-1086)$ & $671(344-1027)$ & 0.443 \\
\hline Blood loss (ml) & $\begin{array}{c}4500 \\
(1000-30800)\end{array}$ & $1300(500-2000)$ & $<0.001$ \\
\hline Unit of blood transfusion & $5(1-56)$ & 0 & \\
\hline Hospital mortality & $2(3.2 \%)$ & $1(2.7 \%)$ & 1 \\
\hline Complication (Clavien-Dindo grade IIIA or above) & $30(48.4 \%)$ & $8(21.6 \%)$ & 0.008 \\
\hline Hospital stay (d) & $17(8-84)$ & $11(1-65)$ & $<0.001$ \\
\hline
\end{tabular}

Data are presented in median (range) or number (percentage). 
Table 2. Results of univariate and multivariate analyses of risk factors associated with overall survival

\begin{tabular}{|c|c|c|c|c|c|}
\hline \multirow[t]{2}{*}{ Variable } & \multicolumn{2}{|c|}{ Univariate analysis } & \multicolumn{3}{|c|}{ Multivariate analysis } \\
\hline & $\begin{array}{c}\text { Hazard ratio (95\% } \\
\text { confidence interval) }\end{array}$ & $\mathrm{P}$ & Hazard ratio & $\begin{array}{c}\text { 95\% confidence } \\
\text { interval }\end{array}$ & $\mathrm{P}$ \\
\hline Age & $\begin{array}{c}0.9986 \\
(0.896-1.086)\end{array}$ & 0.780 & & & \\
\hline Sex & $0.754(0.157-3.631)$ & 0.725 & & & \\
\hline Hepatitis B virus infection & $0.867(0.178-4.216)$ & 0.860 & & & \\
\hline Hepatitis C virus infection & $0.411(0.083-2.034)$ & 0.276 & & & \\
\hline Model for End-stage Liver Disease score & $1.060(0.984-1.142)$ & 0.125 & & & \\
\hline Alpha-fetoprotein & $1.000(0.999-1.001)$ & 0.747 & & & \\
\hline Graft type (live donor v. deceased donor graft) & $1.063(0.263-4.302)$ & 0.932 & & & \\
\hline Blood transfusion & $1.059(0.995-1.128)$ & 0.073 & & & \\
\hline Complication (Clavien-Dindo grade IIIA or above) & $\begin{array}{c}7.108 \\
(1.455-34.712)\end{array}$ & 0.015 & 7.108 & $1.45-34.71$ & 0.015 \\
\hline Cold ischemic time & $1.000(0.995-1.005)$ & 0.963 & & & \\
\hline Warm ischemic time & $1.011(0.967-1.058)$ & 0.620 & & & \\
\hline Operation duration & $1.002(0.999-1.006)$ & 0.233 & & & \\
\hline Number of tumor & $1.445(0.549-3.804)$ & 0.456 & & & \\
\hline
\end{tabular}




\section{References}

1. Yamamoto, J., et al., Perioperative blood transfusion promotes recurrence of hepatocellular carcinoma after hepatectomy. Surgery, 1994. 115(3): p. 303-9.

2. Asahara, T., et al., Perioperative blood transfusion as a prognostic indicator in patients with hepatocellular carcinoma. World J Surg, 1999. 23(7): p. 676-80.

3. Makino, Y., et al., The influence of perioperative blood transfusion on intrahepatic recurrence after curative resection of hepatocellular carcinoma. Am J Gastroenterol, 2000. 95(5): p. 1294-300.

4. Hanazaki, K., et al., Perioperative blood transfusion and survival following curative hepatic resection for hepatocellular carcinoma. Hepatogastroenterology, 2005. 52(62): p. 524-9.

5. Katz, S.C., et al., Operative blood loss independently predicts recurrence and survival after resection of hepatocellular carcinoma. Ann Surg, 2009. 249(4): p. 617-23.

6. Shiba, H., et al., Negative impact of blood transfusion on recurrence and prognosis of hepatocellular carcinoma after hepatic resection. J Gastrointest Surg, 2009. 13(9): p. 1636-42.

7. Shiba, H., et al., Practice to minimize the use of blood products improve outcome after hepatic resection for hepatocellular carcinoma. Hepatogastroenterology, 2013. 60(127): p. 1681-3.

8. Yanaga, K., et al., Hepatic resection for hepatocellular carcinoma in elderly patients. Am J Surg, 1988. 155(2): p. 238-41.

9. Nagao, T., et al., Hepatic resection for hepatocellular carcinoma. Clinical features and long-term prognosis. Ann Surg, 1987. 205(1): p. 33-40.

10. Tralhao, J.G., et al., Resection of hepatocellular carcinoma: the effect of surgical margin and blood transfusion on long-term survival. Analysis of 209 consecutive patients. Hepatogastroenterology, 2007. 54(76): p. 1200-6.

11. Sugita, S., et al., Prognosis and postoperative lymphocyte count in patients with hepatocellular carcinoma who received intraoperative allogenic blood transfusion: a retrospective study. Eur J Surg Oncol, 2008. 34(3): p. 339-45.

12. Foster, R.S., Jr., et al., Adverse relationship between blood transfusions and survival after colectomy for colon cancer. Cancer, 1985. 55(6): p. 1195-201.

13. Younes, R.N., A. Rogatko, and M.F. Brennan, The influence of intraoperative hypotension and perioperative blood transfusion on disease-free survival in patients with complete resection of colorectal liver metastases. Ann Surg, 1991. 214(2): p. 107-13.

14. Tartter, P.I., The association of perioperative blood transfusion with colorectal cancer recurrence. Ann Surg, 1992. 216(6): p. 633-8.

15. Parrott, N.R., et al., Effect of perioperative blood transfusion on recurrence of colorectal cancer. Br J Surg, 1986. 73(12): p. 970-3.

16. Blumberg, N., M.M. Agarwal, and C. Chuang, Relation between recurrence of cancer of the colon and blood transfusion. Br Med J (Clin Res Ed), 1985. 290(6474): p. 1037-9.

17. Stephenson, K.R., et al., Perioperative blood transfusions are associated with decreased time to recurrence and decreased survival after resection of colorectal liver metastases. Ann Surg, 1988. 208(6): p. 679-87.

18. Little, A.G., et al., Perioperative blood transfusion adversely affects prognosis of patients with stage I non-small-cell lung cancer. Am J Surg, 1990. 160(6): p. 630-2; discussion 633.

19. Tartter, P.I., L. Burrows, and P. Kirschner, Perioperative blood transfusion adversely affects prognosis after resection of Stage I (subset N0) non-oat cell lung cancer. J Thorac Cardiovasc Surg, 1984. 88(5 Pt 1): p. 659-62. 
20. Hyman, N.H., et al., Blood transfusions and survival after lung cancer resection. Am J Surg, 1985. 149(4): p. 502-7.

21. Moores, D.W., S. Piantadosi, and M.F. McKneally, Effect of perioperative blood transfusion on outcome in patients with surgically resected lung cancer. Ann Thorac Surg, 1989. 47(3): p. 346-51.

22. Crowe, J.P., et al., Breast cancer survival and perioperative blood transfusion. Surgery, 1989. 106(5): p. 836-41.

23. Kaneda, M., et al., Adverse affect of blood transfusions on survival of patients with gastric cancer. Transfusion, 1987. 27(5): p. 375-7.

24. Fong, Y., et al., Association of perioperative transfusions with poor outcome in resection of gastric adenocarcinoma. Am J Surg, 1994. 167(2): p. 256-60.

25. Schiergens, T.S., et al., Impact of perioperative allogeneic red blood cell transfusion on recurrence and overall survival after resection of colorectal liver metastases. Dis Colon Rectum, 2015. 58(1): p. 74-82.

26. de Villa, V. and C.M. Lo, Liver transplantation for hepatocellular carcinoma in Asia. Oncologist, 2007. 12(11): p. 1321-31.

27. Tripodi, A. and P.M. Mannucci, The coagulopathy of chronic liver disease. N Engl J Med, 2011. 365(2): p. 147-56.

28. Hannaman, M.J. and Z.G. Hevesi, Anesthesia care for liver transplantation. Transplant Rev (Orlando), 2011. 25(1): p. 36-43.

29. Chok, K.S., et al., Late recurrence of hepatocellular carcinoma after liver transplantation. World J Surg, 2011. 35(9): p. 2058-62.

30. Dai, W.C., et al., Good longterm survival after primary living donor liver transplantation for solitary hepatocellular carcinomas up to $8 \mathrm{~cm}$ in diameter. HPB (Oxford), 2014. 16(8): p. 749-57.

31. Dindo, D., N. Demartines, and P.A. Clavien, Classification of surgical complications: a new proposal with evaluation in a cohort of 6336 patients and results of a survey. Ann Surg, 2004. 240(2): p. 205-13.

32. Qian, Y.B., G.H. Cheng, and J.F. Huang, Multivariate regression analysis on early mortality after orthotopic liver transplantation. World J Gastroenterol, 2002. 8(1): p. 128-30.

33. Li, C., et al., Risk factors for in-hospital mortality of patients with high model for end-stage liver disease scores following living donor liver transplantation. Ann Hepatol, 2012. 11(4): p. 471-7.

34. Ramos, E., et al., Intraoperative red blood cell transfusion in liver transplantation: influence on patient outcome, prediction of requirements, and measures to reduce them. Liver Transpl, 2003. 9(12): p. 1320-7.

35. Feltracco, P., et al., Blood loss, predictors of bleeding, transfusion practice and strategies of blood cell salvaging during liver transplantation. World J Hepatol, 2013. 5(1): p. 1-15.

36. Nardo, B., et al., Red blood cell transfusion in liver transplantation: a case-control study. Transplant Proc, 2005. 37(10): p. 4389-92.

37. Hendriks, H.G., et al., Intraoperative blood transfusion requirement is the main determinant of early surgical re-intervention after orthotopic liver transplantation. Transpl Int, 2005. 17(11): p. 673-9.

38. Boyd, S.D., et al., Alloimmunization to red blood cell antigens affects clinical outcomes in liver transplant patients. Liver Transpl, 2007. 13(12): p. 1654-61.

39. Bang, S.R., et al., Predictors of high intraoperative blood loss derived by simple and objective method in adult living donor liver transplantation. Transplant Proc, 2010. 42(10): p. 4148-50.

40. Cacciarelli, T.V., et al., Effect of intraoperative blood transfusion on patient outcome in 
hepatic transplantation. Arch Surg, 1999. 134(1): p. 25-9.

41. Yuasa, T., et al., Intraoperative blood loss during living donor liver transplantation: an analysis of 635 recipients at a single center. Transfusion, 2005. 45(6): p. 879-84.

42. Rana, A., et al., Blood transfusion requirement during liver transplantation is an important risk factor for mortality. J Am Coll Surg, 2013. 216(5): p. 902-7.

43. Kaido, T., et al., The influence of intraoperative homologous blood transfusion on prognosis after liver transplantation for hepatocellular carcinoma. Hepatogastroenterology, 2009. 56(91-92): p. 808-12.

44. Kuroda, S., et al., No impact of perioperative blood transfusion on recurrence of hepatocellular carcinoma after hepatectomy. World J Surg, 2012. 36(3): p. 651-8.

45. Harada, N., et al., Blood Transfusion is Associated with Recurrence of Hepatocellular Carcinoma After Hepatectomy in Child-Pugh Class A Patients. World J Surg, 2015. 39(4): p. 1044-51.

46. Fan, S.T., et al., Continuous improvement of survival outcomes of resection of hepatocellular carcinoma: a 20-year experience. Ann Surg, 2011. 253(4): p. 745-58.

47. Aramaki, O., et al., Decreased blood loss reduces postoperative complications in resection for hepatocellular carcinoma. J Hepatobiliary Pancreat Sci, 2014. 21(8): p. 585-91.

48. Chok, K.S., et al., Impact of postoperative complications on long-term outcome of curative resection for hepatocellular carcinoma. Br J Surg, 2009. 96(1): p. 81-7.

49. Farid, S.G., et al., Correlation between postoperative infective complications and long-term outcomes after hepatic resection for colorectal liver metastasis. Ann Surg, 2010. 251(1): p. 91-100.

50. Mynster, T., et al., Effects of the combination of blood transfusion and postoperative infectious complications on prognosis after surgery for colorectal cancer. Danish RANX05 Colorectal Cancer Study Group. Br J Surg, 2000. 87(11): p. 1553-62.

51. Alfieri, S., et al., Avoiding early postoperative complications in liver surgery. A multivariate analysis of 254 patients consecutively observed. Dig Liver Dis, 2001. 33(4): p. 341-6.

52. Kooby, D.A., et al., Influence of transfusions on perioperative and long-term outcome in patients following hepatic resection for colorectal metastases. Ann Surg, 2003. 237(6): p. 860-9; discussion 869-70.

53. Ferraris, V.A., E.Q. Ballert, and A. Mahan, The relationship between intraoperative blood transfusion and postoperative systemic inflammatory response syndrome. Am J Surg, 2013. 205(4): p. 457-65.

54. DiNorcia, J., et al., Reoperative complications after primary orthotopic liver transplantation: a contemporary single-center experience in the post-model for end-stage liver disease era. J Am Coll Surg, 2014. 219(5): p. 993-1000. 